\title{
Learning French as a foreign language in a globalised world: an empirical critique of the L2 Motivational Self System
}

\author{
Leigh Oakes $^{\mathrm{a}} \&$ Martin Howard ${ }^{\mathrm{b}}$ \\ ${ }^{a}$ School of Languages, Linguistics and Film, Queen Mary University of London, UK; \\ ${ }^{\mathrm{b}}$ Department of French, University College Cork, Ireland
}

\begin{abstract}
While the L2 Motivational Self System (L2MSS) has been extensively investigated among learners of English, this study explores through a crosslinguistic lens its applicability to learners of a language other than English (LOTE), in this case French. Quantitative survey analysis among 522 university learners of French and English in two European countries (Sweden and Poland) suggests that while the framework is relevant in the case of learners of French, other motivation constructs are also at play. The L2MSS supposedly subsumes various traditional motivational constructs (e.g. integrative orientation, instrumental orientation), yet there is evidence to suggest that these were perceived as distinct constructs in their own right, especially by the learners of French. Even a strong form of integrative orientation was found to play an active role among the learners of French who had spent time in a francophone country and had learnt the language for longer. As such, the article argues for a more comprehensive approach to second language (L2) motivation theory that is also sensitive to factors at play in the specific case of LOTEs.
\end{abstract}

\section{Keywords}

L2 motivation, L2 Motivational Self System, ideal L2 self, integrative orientation, ought-to L2 self, L2 French

\section{Introduction}

Prompted by the linguistic consequences of globalisation and new poststructuralist conceptions of identity, the L2 Motivational Self System (L2MSS) (Dörnyei 2005, 2009) is seen as especially suited to the study of motivation to learn the global lingua franca of the current era. Indeed, the focus on English as a foreign language (EFL) that has characterised the majority of L2 motivational research over the last decade explains to a large extent the interest attracted by this new theoretical paradigm. Designed as a reconceptualisation especially of Gardner's (e.g. 2010) integrative motive, the model's core notion of the ideal L2 self shifts the focus away from comparisons with L1 speakers of the target language to the learner's own self-image as a competent L2 speaker in the future. It is thus deemed more appropriate for accounting for motivation to learn English, associated increasingly less with its L1 speakers and more with new global - and especially youth - identities. But how suitable is the ideal L2 self construct for understanding motivation to learn other foreign languages that continue to be associated with their particular target-language communities? Moreover, is the large-scale repudiation of integrative motivation really justified in the case of these languages? And what of university-level learners, who are more likely to have contact with target-language speakers and cultures than the younger learners who were the focus of the original studies that led to the development of the L2MSS (see Dörnyei, Csizer and Németh 2006)? 
This study responds to the now recognised need for more research focusing on motivation to learn languages other than English (LOTEs) in the new global era. In their introduction to a recent special issue on this "largely uncharted area of language learning motivation”, Ushioda and Dörnyei $(2017,452)$ identified two core questions: “(a) How far are current mainstream theoretical perspectives adequate to account for motivation to learn languages other than English? and (b) What impact does global English have on motivation to learn other second or foreign languages in a globalized yet multicultural and multilingual world?" Part of a broader study of motivation among university learners of French, this article addresses the first of these questions (Howard and Oakes, forthcoming focuses on the second), analysing the quantitative results of a questionnaire distributed in two European countries (Sweden and Poland) among 522 university learners of French and English. Specifically, it compares the relevance of the ideal L2 self and ought-to L2 self constructs for the two target-language cohorts, and examines how the former notion relates to the more traditional motivational constructs it was designed to replace and to a further analogous construct that nonetheless avoids reference to the self (desire for proficiency). It also investigates whether the rejection of integrative orientation is justified for university learners of French. Finally, as a means of further probing the essence of the main motivational constructs of interest, the article discusses the effect of two additional factors designed to tap into the dynamic nature of motivation and conceptions of the self in particular, namely time spent in a country where the L2 is spoken and length of study. The overall aim is to provide an empirical comparative critique in a LOTE and EFL context of the two self-guides that make up the L2MSS, so as to contribute to the further development of L2 motivation theory, which in recent years has been disproportionately shaped by learners of EFL.

\section{The L2 Motivational Self System}

\section{Principles}

Having enjoyed a central role in L2 motivational research over the last decade (e.g. Dörnyei 2005, 2009, 2010; Dörnyei and Ushioda 2011; Dörnyei and Ryan 2015), the L2MSS has possibly become the pre-eminent theoretical paradigm in the field. Its origins lie partly in advances in research into the self, particularly in possible selves theory, which identifies three main representations that individuals have of themselves in the future: "what they might become, what they would like to become, and what they are afraid of becoming" (Markus and Nurius 1986, 954). Rather than focus on how past experiences shape an individual's conception of the self at present, this theory is particularly relevant for motivational research in that it represents "a dynamic, forward-pointing conception that can explain how someone is moved from the present toward the future" (Dörnyei 2009, 11). The latter two possible selves mentioned above - the 'ideal' and 'feared' selves - are said to serve guiding functions that motivate the individual. Advancing a similar idea, self-discrepancy theory (Higgins 1987) postulates that individuals are motivated by a desire to reduce discordance between their actual self-concept and their ideal self (the representation of the attributes they would like to possess, of their hopes, aspirations and wishes) and/or their ought self (the representation of the attributes they believe they should possess, of their sense of duty, obligation and responsibility). Applying these concepts to L2 attributes, the L2MSS identifies two L2 self-guides: the ideal L2 self and the ought-to L2 self. The main hypothesis underlying the model is that "if proficiency in the target language is part and parcel of one's ideal or ought-to self, this will serve as a powerful motivating factor to learn the language because of a psychological desire to reduce the discrepancy between our current and possible future selves" (Ushioda and Dörnyei 2009, 4). Further research has reiterated that these two 
L2 self-guides should not be viewed as static constructs, but rather as dynamic targets or "moving pictures" (Henry 2015). They might thus be expected to evolve for example as learners progress in their studies or as a result of intensive contact with L1 speakers, such as through time spent abroad. ${ }^{1}$

Both the ideal L2 self and the ought-to L2 self seek to incorporate traditional motivational constructs discussed in the literature. First and foremost, the ideal L2 self is intended as a reconceptualisation of integrative motivation, which encompasses the related notions of integrativeness and integrative orientation, all three concepts involving some form of emotional identification with the native L2 community (Gardner 2001). ${ }^{2}$ Already during the 1980s, questions arose about the suitability of this underlying idea especially in foreign language (FL) as opposed to L2 learning contexts. While some stressed the need to distinguish strong (belonging) and weak (affiliation) versions (McDonough 1986, 158), others highlighted the inappropriateness of the notions with regard to the learning of English in particular. For example, a study of attitudes among Asian students observed that "they are not learning English so that they can change themselves and become more like native speakers" (Shaw 1983, 24), concluding that "the whole aspect of integrative motivation should be re-examined in terms of a desire among learners to join an indigenous group of English language speakers [such as a local elite] or a vague international one rather than a group of foreign native speakers" (Shaw 1983, 33). Since then, others have made similar observations about the "imagined community" (Norton 2001) of L2 speakers associated with English as it becomes a basic form of literacy around the world (e.g. Coetzee-Van Rooy 2006; McClelland 2000; Sridhar and Sridhar 1992; Yashima 2002). As Lamb (2004, 3) notes, "as English loses its association with particular Anglophone cultures and is instead identified with the powerful forces of globalization, the desire to 'integrate' loses its explanatory power in many EFL contexts." In the original Hungarian studies that led to the development of the L2MSS, Dörnyei and his associates developed this critique further, extending it to the learning of other FLs (see Dörnyei, Csizér and Németh 2006). While integrativeness was found to be the principal motivating factor among those examined, this was considered to make no theoretical sense in so far as there was nothing into which the participants could meaningfully integrate, since they had only limited contact with target-language visitors to Hungary. The ultimate reconceptualisation of integrativeness was thus justified on the grounds that "the motivation dimension captured by the term is not so much related to any actual, or metaphorical, integration into an L2 community as to some more basic identification process within the individual's self-concept" (Dörnyei and Csizér 2002, 453).

The second traditional motivational construct that the L2MSS seeks to incorporate is instrumental orientation, divided into two types by Dörnyei following Higgins $(1987,1998)$. When the practical reasons that motivate a language learner seek to promote a desired endstate (instrumentality-promotion), they purportedly fall within the scope of the ideal L2 self. When they seek to prevent a feared end-state (instrumentality-prevention), they are said to belong, however, to the realm of the ought-to L2 self. This distinction and the respective correlations with the two self-guides have found empirical support (e.g. Taguchi, Magid and Papi 2009).

Finally, both self-guides ostensibly incorporate motivational constructs that form the core of self-determination theory (Deci and Ryan 1985; Ryan and Deci 2000, 70). Focusing on the extent to which individual behaviour is self-motivated, this theory proposes a continuum from intrinsic motivation, through extrinsic orientation to amotivation, and has been applied to L2 motivation (e.g. Noels 2001; Noels et al. 2000). While intrinsic motivation derives from the inherent pleasure associated with language learning (e.g. satisfaction of curiosity, intellectual stimulation, thirst for knowledge, sense of accomplishment), extrinsic motivation is divided into four types depending on the degree to which it is externally 
derived: external regulation (e.g. meeting parental expectations), introjected regulation (e.g. wanting to avoid feelings of embarrassment caused by failure), identified regulation (e.g. perceiving a language as useful), integrated regulation (e.g. wanting to be educated). Dörnyei $(2009,14)$ notes how the first two of these fall within the concept of the ought-to L2 self, while the latter two, being more internalised, form part of the ideal L2 self. However, the boundaries between the types of extrinsic motivation, and even between integrated regulation and intrinsic motivation, are difficult to determine. Indeed, some of the responses to the question "Why are you learning Spanish?" classified by Noels $(2001,46)$ as examples of intrinsic motivation could equally reflect an imagined future self: "The exciting ability to become bilingual", "I enjoy the language, I am good at it, and I want to become fluent in speaking Spanish". Empirical studies have also pointed to the possibility of some conceptual overlap between the ideal L2 self and intrinsic motivation (e.g. Oakes 2013).

\section{Problems}

Despite its popularity, there are two main problems with the L2MSS relevant to the present study. First, while the framework supposedly "broadens the scope of the theory to make it applicable in diverse language learning environments in our globalized world" (Dörnyei $2010,75)$, the reality is that $72.67 \%$ of motivation research published in 2005-2014 was concerned with English (Boo, Dörnyei and Ryan 2015). While this might seem understandable given the latter's rise as the new global lingua franca, the fact that the field has undergone such a profound paradigm shift prompted by the learning of one very particular language is potentially problematic. Like basing sociolinguistic theory on the language usage solely of men, there is a real risk of generalising to all FLs the very specific motivations for learning EFL. Aware of this potential, Dörnyei $(2005,118-119)$ suggests a possible two-tier approach that treats motivation for learning EFL differently. Nonetheless, this has not stopped L2 motivational research on EFL impacting on that concerning other languages, spurred most recently by the multilingual/critical turn that is currently making its mark on the field. For example, Ushioda (2017) suggests that the theoretical advances in L2 motivation theory prompted by EFL could usefully serve to encourage a shift away from native speaker models more generally, despite there being a much higher likelihood that LOTE learners will ultimately interact with native speakers and see themselves as part of a community that includes them. "A person trying to learn Danish, for example, would most likely be thinking about a localized community rather than imagining themselves as a global citizen" (Al-Hoorie 2017, 7). That the notion of the ideal L2 self seeks not so much to complement integrative motivation as to replace it makes talking about the latter at the very least difficult (Gardner 2005, 8). As MacIntyre, MacKinnon and Clément (2009, 45-46) warn:

if the social psychological and political dimensions of language are drained away as the bathwater, we must be careful not to lose the conceptual baby, which is the relevance of those individual differences in the motivations to communicate with people who speak the target language.

Indeed, integrative motivation has been shown to increase following a period of study abroad, which typically correlates positively with interaction with target-language speakers (e.g. Isabelli-García 2006, Hernández 2010, Juan-Garau, Salazar-Noguerra and Prieto-Arranz 2014). If the field heeds the call for more research on motivation to learn LOTEs, which are inarguably more closely associated with target-language communities, integrative 
orientations may well find themselves resurfacing as important sources of motivation (AlHoorie 2017, 7).

The second problem with the L2MSS for our purposes concerns the participants of the original Hungarian studies (see Dörnyei, Csizér and Németh 2006). To their credit, Dörnyei and his associates examined motivations to learn five foreign languages: English, German, French, Italian and Russian. However, the fact that the participants were 13-14-year-old final-year primary school pupils limits somewhat the generalisability of the results. The concept of integrativeness in its original guise may well be more relevant for older participants, who have learnt the target language for longer and who have more opportunities for meaningful contact with members of the associated target-language community (e.g. through time spent in countries where the L2 is spoken, friendships with native speakers). Indeed, in all three Hungarian studies, the participants did not report particularly frequent encounters with foreign visitors to Hungary who spoke the languages examined (Dörnyei, Csizér and Németh 2006, 120). Only for German tourists did the frequency of self-reported encounters fall on the more positive side of the half-way mark on the 5-point Likert scale used, albeit not by much. There is also evidence to suggest that the notion of the ought-to L2 self may also be age-relevant. While this may be well suited to school-age language learners, who may not have a choice in what language they are learning or even in whether they learn a language at all, studies of motivation among older, more independent university-age learners have not revealed the ought-to L2 self to be a particularly apposite concept (e.g. Busse and Williams 2010; Oakes 2013).

\section{Aims of the study}

Against this background, the study presented here sought to provide a critical assessment of the two L2MSS self-guides, comparing motivations to learn French and English among university learners in two European countries (Sweden and Poland). The specific research questions (RQs) were:

RQ1 a) Does the degree to which the learners claim to be motivated by the ideal L2 self vary according to target language (French versus English)? b) How do learner ratings of the ideal L2 self compare and correlate with those of the more traditional motivational constructs the ideal L2 self seeks to incorporate?

RQ2 a) Are the learners of French more integratively motivated than the learners of English? b) Is a weaker form of integrative orientation deemed more important than a stronger form?

RQ3 To what extent are university learners motivated by the ought-to L2 self?

RQ4 Do learners' ratings of the main motivational constructs of interest - ideal L2 self, integrative orientation and the ought-to L2 self - vary as a product of time spent in a country where the target language is spoken and length of study?

\section{Methodology}

\section{Instrument}

The study made use of a questionnaire designed for learners of French and English respectively. Following a brief introduction to the study with instructions on how to complete the questionnaire, the first part contained a number of randomly ordered items designed to measure the ratings of seven motivational constructs: the ideal L2 self, the ought-to L2 self, strong integrative orientation, weak integrative orientation, instrumental (promotion) 
orientation, intrinsic motivation and desire for proficiency (see Appendix). Most of these items were taken directly or adapted from previous studies (Oakes 2013; Busse and Williams 2010; Gardner, Tremblay and Masgoret 1997; Noels 2001, 2009; Noels et al. 2000; Ryan 2008; Taguchi, Magid and Papi 2009). In line with RQ2b, the items relating to a weak form of integrative orientation were formulated specifically for the present study. Intended to reflect a genuine affinity with the L2 culture, they were not limited solely to the consumption of cultural products in the L2, as was the case with the "media usage"/"cultural interest" scale used in the Hungarian studies (Dörnyei and Clément 2001; Dörnyei, Csizér and Németh 2006). All these items sought responses on a 5-point Likert-like scale which included both numeric and text labels $(1=$ disagree completely, $2=$ disagree partially, $3=$ neither agree nor disagree, $4=$ agree partially, $5=$ agree completely). The final part of the questionnaire contained a series of items eliciting information about the profiles of the respondents: age, sex, L1 and self-reported proficiency (see Appendix for individual items comprising the scale). A further set of questions enquired about the secondary independent variables mentioned in RQ4: whether the respondents had spent time in a country where the L2 was spoken (excluding short holidays, which are less likely to facilitate more intensive, prolonged contact with target-language speakers) and length of study.

\section{Data collection and participants}

The two versions of the questionnaire were distributed between October 2016 and February 2017 in two universities in Sweden and two in Poland (in Polish in Poland and English in Sweden, reflecting the widespread status of English in that country). Local research assistants contacted French and English departments and individual teachers to gain access to classes where the questionnaire was distributed, with some data also being collected through an online version of the questionnaire publicised via departmental emails. Following inputting of the data, L1 speakers of the two target languages were removed from the data set for their presumably different motivations for studying the target language. Similarly, to eliminate any intergenerational differences, the study only retained the data from respondents aged 35 years and under, reflecting an extended youth today (St-Laurent 2008, 20). This resulted in a total of 522 respondents, aged 17 to $35(M=22.27, S D=3.56)$ distributed in the two countries and among learners of the two target languages as in Table 1.

\section{INSERT TABLE 1 HERE}

As is generally the case with foreign language learning, a greater number of respondents were female for each target language: French $(72.1 \%$ versus $25.7 \%)$ and English $(69.6 \%$ versus $29.7 \%$ ). Reflective of early school exposure, the learners of English had been studying the target language for longer than the learners of French (see Table $2 ; \chi^{2}(2)=192.17, p<.001$ ).

\section{INSERT TABLE 2 HERE}

In line with this trend, the learners of English also reported on average greater proficiency in the target language: $M=3.99, S D=0.75$ versus $M=2.92, S D=.98$ for the learners of French $(1=$ very weak, $2=$ weak, $3=$ average, $4=$ good, $5=$ very good; $t(508)=-12.78, p<.001, d$ $=-1.14)$. Finally, fewer respondents had spent time in a country where the L2 was spoken than had not, with no significant differences between the learners of each language: $21.4 \%$ ( $n$ $=47)$ versus $78.6 \%(n=173)$ for French and 16.2\% $(n=47)$ versus $83.8 \%(n=244)$ for English $\left(\chi^{2}(1)=2.27, p=.13\right)$. 


\section{Preliminary analyses}

As a first step in the data analysis, factor analysis was conducted in Jasp to explore the structure of the motivational factors used. Considered more accurate than the Kaiser 1 rule or scree plots, parallel analysis was the method chosen to identify numbers of factors (Velicer, Eaton and Fava 2000; Lance, Butts and Michels 2006). As the latter were assumed to be intercorrelated, oblique rotation (Promax) was used for the interpretation of the results. Whereas seven factors were theorised, only six were extracted from the factor analysis. That many items for the ideal L2 self and intrinsic motivation loaded onto a single factor raised discriminant validity concerns, highlighting the need for greater conceptual clarity between the two sets of commonly used items. A decision was thus made to exclude the four items designed to measure intrinsic motivation, not because this construct was deemed less valid than the ideal L2 self, but rather because the aim of the study was specifically to test the L2MSS self guides. A further three items (indicated with an asterisk in the Appendix) were also excluded on the basis of the factor analysis results. While something similar to item 17 was included in Gardner's $(1985,179)$ Attitude/Motivation Test Battery alongside other instrumental orientations, this did not load well onto any factor. As for items 24 and 27, these did not load onto the strong and weak integrative factors as expected, but rather onto the factor comprising the items for the ideal L2 self (at .34 and .62 respectively). The results of the final factor analysis are shown in Table 3, while the Cronbach alpha scores for the final scales $($ all $>.7)$ are indicated in the Appendix. The subsequent analyses (independent and dependent samples $t$-tests, ANOVAs and correlations) were conducted in SPSS, with Bonferroni corrections applied for multiple comparisons.

\section{INSERT TABLE 3 HERE}

\section{Results}

Table 4 compares the ratings for the various motivational constructs examined across the two target-language cohorts. Drawing on this table, the presentation that follows is structured according to the main constructs of interest as reflected in RQs1-3, namely the ideal L2 self, integrative orientation (in its strong and weak variants) and the ought-to L2 self. These constructs are also considered in relation to time spent abroad and length of study (RQ4).

\section{INSERT TABLE 4 HERE}

\section{Ideal L2 self}

In response to RQ1a, no significant difference was observed regarding the ratings for the ideal L2 self between the learners of French and English. As for RQ1b, for both sets of learners, the ideal L2 self was rated more highly than both strong integrative orientation $(t(224)=-19.56, p<.001, d=-1.30$ for French and $t(293)=-24.16, p<.001, d=-1.41$ for English) and weak integrative orientation $(t(225)=-4.29, p<.001, d=-0.29$ for French and $t(295)=-11.65, p<.001, d=-0.68$ for English). Notwithstanding these positive comparisons with integrative orientation, no significant differences were observed between the ratings for the ideal L2 self and instrumental orientation $(t(222)=-1.15, p=.250$ for French and $t(289)=1.03, p=.305$ for English), and both sets of learners deemed the ideal L2 self a less important source of motivation than desire for proficiency, the latter serving as an analogous construct designed to test a desire to become a competent L2 speaker in the future, 
but without specific reference to the self $(t(225)=10.96, p<.001$ for French and $t(289)=$ 2.63, $p=.009$ for English).

Correlations offered a further means of addressing RQ1b by exploring the relationship between the ideal L2 self and the motivational constructs it seeks to incorporate (see Table 5). Indeed, the "substantial positive correlations" found between the ideal L2 self and integrativeness by previous studies have been used as grounds for suggesting that "the two variables do indeed tap into the same underlying construct domain" (Dörnyei 2010, 80). The positive correlation observed between the ideal L2 self and desire for proficiency in the present study is not surprising, considering the intended conceptual similarities. The strong positive correlations between the ideal L2 self and instrumental orientation and weak integrative orientation respectively might potentially suggest some link with these more traditional constructs. However, the weaker positive correlation between the ideal L2 self and strong integrative orientation, which was not even significant in the case of the English learners $(r=.09, p=.133)$, would seem to suggest that these two notions are distinct.

\section{INSERT TABLE 5 HERE}

A still further means of examining the relationship between the ideal L2 self and the other motivational constructs it seeks to incorporate consisted of comparing means plots across the two target-language cohorts (see Figure 1). In line with the interpretation of the correlations, the pattern for instrumental orientation mirrors that of the ideal L2 self, rising for the English learners relative to the French learners, thus making it conceivable that there is a relationship between the two constructs. However, the fact that the same pattern is not observed for the other three constructs makes it impossible to make similar claims for them. Even leaving aside strong integrative orientation, for which no significant difference was found between the two sets of language learners (see Table 4), the ratings for weak integrative orientation and desire for proficiency clearly drop for the English learners compared with the French learners, whereas the reverse would be expected in the case of a possible conceptual link. The implication is that these other constructs - strong integrative orientation included - cannot simply be superseded by the notion of the ideal L2 self. That the two sets of learners responded to them differently when compared with the ideal L2 self gives these constructs legitimacy, suggesting that they are perceived as distinct constructs that are meaningful in their own right.

\section{INSERT FIGURE 1 HERE}

Figure 1. Patterns of motivational constructs across French and English learners

Finally, insight into the dynamic nature of the ideal L2 self was sought by examining the effect of the two secondary independent variables mentioned in RQ4: time spent in a country where the target language is spoken and length of study. Considering claims that the ideal L2 self is an evolving concept, these variables were expected to play a role. However, this was not found to be the case. The respondents who had spent time in a target-language country were not significantly more motivated than those who had not: $M=4.35, S D=0.60$ and $M=4.16, S D=0.88$ for French learners $(t(106.46)=1.69, p=.094, d=0.25)$ and $M=$ 4.43, $S D=0.72$ and $M=4.28, S D=0.78$ for English learners $(t(289)=1.21, p=.228, d=$ $0.20)$. Likewise, no significant differences were revealed for the three length-of-study categories examined, either among the French learners $(F(2,217)=1.87, p=.156)$ or the English learners $(F(2,291)=0.05, p=.955)$.

\section{Integrative orientation}


Providing an initial response to RQ2a on whether French learners were more integratively motivated, no significant differences were found between the two sets of learners, who both disagreed that they were learning the target language for strong integrative reasons (see Table 4). However, when defined in weaker terms (RQ2b), the French learners were indeed found to be more integratively motivated than their English counterparts. This weaker variant of integrative orientation was also shown to be a more useful construct for accounting for motivation than the stronger variant for all participants, the differences between reactions to the two variants proving significant for both the French $(t(224)=18.15, p<.001, d=1.21)$ and English learners $(t(293)=19.49, p<.001, d=1.14)$.

Consideration of the effect of the secondary independent factors designed to explore the variable nature of integrative orientation (RQ4) revealed further differences between the two groups of learners. Beginning with time spent abroad, those who had lived in a Frenchspeaking country rated strong integrative orientation more favourably than those who had not, even agreeing slightly that factors related to this construct provided a source of motivation: $M=3.17, S D=1.01$ compared with $M=2.59, S D=0.98(t(217)=3.56, \mathrm{p}<.001$, $d=.59$ ). However, such a distinction was not observed among the English learners: $M=2.79$, $S D=1.10$ and $M=2.55, S D=1.01$ respectively $(t(287)=1.48, p=.140, d=0.23)$. As for weak integrative orientation, time spent abroad was found to have no effect on either group once Bonferroni corrections were applied. Those who had spent time in a French-speaking country were not more motivated by factors related to the construct than those who had not $(M=4.09, S D=0.88$ and $M=3.93, S D=0.90 ; t(218)=1.06, p=.290, d=0.18)$, just like those who had spent time in an English-speaking country were not more motivated than those who had not $(M=3.98, S D=0.78$ and $M=3.72, S D=0.81 ; t(289)=2.03, p=.044, d=$ 0.32 ).

Length of study was also found to have an effect on strong integrative orientation (see Table 6). While differences were found for both sets of learners, the significant finding lay in the direction of the differences. Among the learners of French, the suggested motivating factors related to strong integrative orientation were rated less unfavourably by those who had learnt the language for longer. Bonferroni post hoc comparisons revealed a significant difference between the learners of $<1$ year and those of $>5$ years. However, for the learners of English, the reverse trend was observed, with the same factors rated even more unfavourably by those who had learnt the language for longer. Again, Bonferroni post hoc comparisons revealed a significant difference between the learners of $<1$ year and those of $>$ 5 years. Length of study did not have any significant effect on weak integrative orientation, either for the French $(F(2,217)=0.63, p=.536)$ or English learners $(F(2,291)=1.12, p=$ $.328)$.

\section{INSERT TABLE 6 HERE}

\section{Ought-to L2 self}

In response to RQ3, both sets of learners disagreed that factors related to the ought-to L2 self motivated their language learning (see Table 4). That it was nonetheless the learners of French who disagreed more suggests that, in addition to being a less relevant source of motivation for language learners at university, it may be even less relevant still for learners of a LOTE at this level.

Unlike with the ideal L2 self, the secondary variables designed to explore the dynamic nature of the ought-to L2 self construct (RQ4) had some effect, albeit only on the learners of English. Those who had spent time in an English-speaking country disagreed even more than 
those who had not that factors related to this construct were a source of motivation $(M=2.30$, $S D=0.98$ versus $M=2.73, S D=0.93 ; t(289)=-2.91, p=.004, d=-0.46)$, a distinction not observed among the French learners $(M=2.11, S D=0.98$ and $M=2.18, S D=1.06$ respectively; $t(218)=-0.41, p=.683, d=-0.07)$. Likewise length of study had an effect on the English learners but not on the French learners (see Table 7). Bonferroni post hoc revealed significant differences between those who had learnt English for $<1$ year and the other two length-of-study groups, suggesting that the ought-to L2 self becomes less unimportant for these learners with increased length of study.

\section{INSERT TABLE 7 HERE}

\section{Discussion}

The results presented raise questions about the importance of the motivational constructs investigated as constituents within the learners' motivational profiles, their relevance to different target language groups, and the impact of learning context and time on their relevance. These three questions will be addressed in this section, bearing in mind the specific RQs of the study.

As noted at the outset, the ideal L2 self is often claimed to subsume various other motivational constructs, constituting a more encompassing notion that considers how learners perceive their future selves as L2 users. It was proposed in reaction to questions expressed about the validity of other motivational constructs, the relevance of which is nonetheless highlighted in the results presented above, especially in the case of a LOTE. Indeed, the results point to the complexity of the learners' motivational profiles; all learners agreed on the multifaceted nature of their motivation, such that it was not one but multiple constructs that were seemingly at play in a complementary fashion. In particular, while the ideal L2 self was important in the motivational make-up of both language groups, it was nonetheless desire for proficiency which was ranked most highly among the constructs examined. Notwithstanding that no significant difference was observed between learners' ratings of the ideal L2 self and instrumental orientation, the (albeit lesser) importance assigned to integrative orientation in its weak form suggests that there is nonetheless a role for that construct (RQ2b). Both language groups thus expressed an interest in the target language culture, and this interest was even greater for the learners of French (RQ2a). Furthermore, in the case of the French learners who had spent time abroad, that interest did not exclude a sense of affiliation with the associated culture, indicating the presence even of a stronger form of integrative orientation, which was not the case for the EFL learners (RQ4). In contrast, both groups disagreed that the ought-to L2 self was an important source of motivation (RQ3), raising questions about why external factors assume a lesser role for these specific learners.

Taken together, the results confirm the relevance of the ideal L2 self as demonstrated in a multitude of existing studies, and in this particular case across both language cohorts (RQ1a). Nonetheless, the fact that some other constructs were deemed important to varying degrees, and that their role may differ at least in the case of strong integrative motivation following time spent abroad, points to the need to conceptualise learner motivation through a multidimensional prism, with different constructs contributing to varying degrees depending on language and learning context. While the L2MSS seeks to capture motivation essentially with the aid of two self-guides (plus the L2 learning experience), the results point to the need for a broader range of motivational constructs, the distinct contributions of which may be activated in different ways depending on language and context (RQ1b). In the case of integrative orientation, it was especially noteworthy that the learners distinguished between 
its strong and weak forms, and that such orientations were distinct from the ideal L2 self that purportedly subsumed them.

If, as suggested above, there is a need for a multidimensional conceptualisation of learner motivation, the lack of discriminant validity observed between the ideal L2 self and intrinsic motivation also calls for further investigation. Considering the established nature of the items used to measure intrinsic motivation, the problem may lie with the items used to measure the ideal L2 self. Indeed, Al-Hoorie (2018: 736) argues that the wording of the items which have been used to date to measure the self-guides is too ambiguous and does not sufficiently emphasise their main distinguishing feature, namely the discrepancy between a current state and a desired future state. Indeed, it is not difficult to see how the wording of some items used to measure the ideal L2 self in the present study (e.g. 'being able to converse in French/English is an important part of the person I want to become' and 'learning French/English is one of the most important aspects of my life') does not sufficiently insist on the forward-looking nature of the ideal L2 self construct to distinguish it clearly from intrinsic motivation. The findings of the current study thus also point to the need for further developmental work on the scales used to measure the self-guides.

A further point concerns the ought-to L2 self (RQ3). That this construct was deemed unimportant by both groups of learners, and especially by the learners of French, begs the question of its validity, particularly in the case of a LOTE. Others have also questioned the status of the ought-to L2 self with regard to its ability to predict intended learning effort and actual achievement (Al-Hoorie 2018). Even if external pressures undoubtedly exist, "in many language contexts they lack the energizing force to make a difference in actual motivated learner behaviors by themselves" (Dörnyei and Chan 2013, 454). It is therefore perhaps less a question of the potential validity of the construct per se than of its greater or lesser relevance in particular contexts. One factor that may play an important role in this respect is age (e.g. Kormos and Csizér 2008), which could explain the rejection of the ought-to L2 self observed in the present study. Unlike children or young adolescents, the university learners who participated in this study were presumably more autonomous individuals who had consciously chosen to study a language, even if they may still have experienced some external pressure to succeed in their chosen programme of study. A more qualitative approach in future research could complement these findings, by further exploring the types of external pressures at play at different ages of acquisition and their relationship to the more internal factors that seem to exert greater influence. Such an approach could also shed light on how perceptions of a range of motivational constructs vary at different stages of learning.

As for the comparison of the motivational profiles across the two language groups, this raises important questions about the universality of the motivational constructs investigated. While the results point to similarities between the groups with regard to the relative ranking of the constructs, there are also differences which may indicate the need for a more nuanced appreciation of the specificity of LOTE learner motivation. In particular, while the learners of English assigned greater importance to the instrumental and ought-to L2 self constructs than the French learners, the opposite pattern emerged in the case of desire for proficiency and weak integrative orientation, with French learners who had resided abroad even displaying a strong form of integrative orientation to some degree. These findings highlight the relatively greater importance of integrative orientation for learners of French compared with learners of English (RQ2a). From a theoretical perspective, it would thus seem premature to dismiss such a construct in the specific context of LOTE learning. As highlighted above, the constructs may work in a complementary as opposed to a supplementary, mutually exclusive, or even 'subsuming' manner.

Finally, the analysis of the secondary variables relating to time spent in the target language community and length of study points to further differences in how the constructs 
may be activated among the learners (RQ4). For example, a period of residence abroad would seem to be linked to a greater sense of strong integrative orientation among the learners of French, which was not apparent for the learners of English, or for either group in the case of weak integrative orientation. Nor was a link between residence abroad and the ideal L2 self apparent across languages, while in the case of the ought-to L2 self, learners of English who had spent time in an English-speaking country disagreed even more that this construct was an important source of motivation. These findings beg the question of why the learning context may relate differently to some motivational constructs than others, and for the learning of some languages but not others. This is a question which is also relevant for length of study, for which significant inter-group variation was also observed. For the learners of French, the strong form of integrative orientation assumed greater importance for those participants who had been learning the language for longer, which was not the case for the learners of English, or for either group with regard to weak integrative orientation. Similar to residence abroad, no effect was observed on the ideal L2 self for length of study, but in contrast, the ought-to L2 self was deemed less unimportant by those participants who had learned English for longer.

Taken together, such mixed findings for the impact of residence abroad and length of study highlight issues about the supposed dynamicity of learner motivation and its contextual conditioning. Indeed, the L2MSS perceives the self-guides, and in particular the ideal L2 self, as dynamic, with several studies offering support (see e.g. chapters in Dörnyei, MacIntyre and Henry 2015). One such study specifically mentions the likely transformative effect on the ideal L2 self of encounters with others "who share certain characteristics of the individual's ideal self" (Henry 2015, 86), that is, encounters of the sort that learners typically have with L1 speakers during a period of residence in the target language country. In the case of the present study, however, neither residence abroad nor length of study was found to impact the ideal L2 self, possibly adding support to other studies (e.g. MacIntyre and Serroul 2015) which suggest that this construct may in fact be less dynamic and subject to contextual conditioning than previously claimed. However, such a finding warrants a number of points which should be taken into account in future research. While the claim of dynamicity seems generally reasonable, assuming that learners' motivation is unlikely to remain static throughout their learning trajectories, evolving as a function of various learner-internal and external contextual factors, the study's findings point to the need for a more nuanced data instrument to tap into that dynamicity and contextual conditioning. While the questionnaire in this study did bring to the fore the dynamicity of some aspects of the learners' motivational profile, its potential to do so in the case of the ideal L2 self would seem more restricted. Other methods might offer further insight, especially through a less cross-sectional than genuinely longitudinal prism that allows for the tracking of specific changes at both a micro level (e.g. over the course of a class) or a more macro level, as learners progress in their diverse learning trajectories. Indeed, this study did not take into account when the residence abroad took place, such that any positive effect that this may have had may have subsided or been reversed by the time of the data collection. In this way, particular data collection methods can lead to a static conceptualisation of the ideal L2 self, with scope for alternative methods to better capture more dynamic understandings of the notion (Henry 2015). Researchers should also be cognisant of the multidimensional nature of dynamicity itself, in terms of whether this is at the micro level (e.g. as motivational changes during a single class period), at a more macro level (e.g. over the course of a period of instruction), or at an even more global macro level (e.g. over the course of a number of years in different learning contexts). It is not inconceivable that the present study captured such motivational dynamics through a long-lens view, but missed some of the short-term transformations affecting learners' motivational profiles. 


\section{Conclusion}

The findings of this study contribute to the field of L2 motivation in a number of ways. First, they highlight the need not so much for motivational research on LOTEs as for better integration between the research on LOTEs and EFL. The theoretical insights gained were only possible because of the comparative approach adopted. While the various motivational constructs examined here may overlap to varying degrees, the comparisons made between learners of French and English suggest that these constructs nonetheless play distinct roles in learners' overall motivational repertoires, as motivational factors that are drawn upon differently depending, for example, on target language, level of study (e.g. school versus university), learning environment (e.g. foreign language classroom versus study and residence abroad) and length of study. Recalling MacIntyre, MacKinnon and Clément's (2009) warning, it would thus indeed seem prudent not to throw out the conceptual baby with the bathwater. In the same way that the notion of the ought-to L2 self would seem to be more relevant in a school rather than university context, so too would integrative orientation appear to be a more apposite construct for learners of French than for learners of EFL. While the dominance of Gardner's socio-educational model and the notion of integrativeness in particular has been accused of stifling the development of the field for many decades (Crookes and Schmidt 1991; Dörnyei 1994), the sheer mass of current motivational research on EFL now risks assigning the same fate to the L2MSS, if the field does not broaden the theory to incorporate insights from the study of motivations to learn LOTEs.

The findings also emphasise the need to explore L2 motivation through a multifaceted prism. The analysis of the effects of secondary independent variables allowed the complexity of the learners' motivational make-up to become apparent in ways that would not have been otherwise possible, thus offering a more nuanced assessment ultimately of theory. By considering specifically the impact of whether the respondents had spent time in a targetlanguage country and length of study, the research confirmed that "motivation [should] not [be] seen as a static attribute of the individual but rather as a dynamic factor that displays continuous fluctuation as it is adapted to the ever-changing parameters of the context" (Dörnyei and Ryan 2015, 84). However, the findings would suggest that even the dynamic nature of motivation is itself complex, with some constructs potentially being more sensitive than others to certain environmental factors, or at least proving easier to capture with particular methods.

In conclusion, while the L2MSS has made great progress in accounting for motivations to learn EFL, it would not yet seem to constitute in and of itself an optimal paradigm for studying motivations to learn LOTEs. Rather, it offers research on these languages a useful complement to more traditional constructs. However, the continued utility of such constructs is underestimated by a field which, judging from an assessment of its current state and future prospects (Dörnyei and Ryan 2015, 103-104), has found a new sense of intellectual confidence as a result of the great strides recently made by studying motivation to learn EFL. Without losing its newly discovered openness to fresh ideas and perspectives, the field would benefit in responding to the call for more research on LOTEs by also recognising the possibility of motivational factors other than the very specific ones that motivate the global citizens of today to learn the lingua franca of our times.

\section{Notes}


1. A third component of the L2MSS model, the L2 learning experience, which relates to the learning environment (e.g. the impact of the teacher, the curriculum, the peer group, the experience of success), is beyond the scope of this article.

2. Dörnyei (1994, 516-517) discusses the confusion around these three related terms, which are often used synonymously, despite the intended conceptual distinctiveness.

\section{Acknowledgements}

The authors would also like to thank Leire Bustamante Törnqvist, Fanny Forsberg Lundell, Jonas Granfeldt, Francis Hult, Erez Levon, Simone Morehed, Urszula Paprocka-Piotrowska, Marlena Siwek, Yang Ye, Hui Zhao and the participants in the study.

\section{Disclosure statement}

No potential conflict of interest was reported by the authors.

\section{Funding}

This research is funded by a Small Grant from the British Academy (SG152011).

\section{Notes on contributors}

Leigh Oakes is Professor of French and Linguistics at Queen Mary University of London, UK. His research focuses on language policy and planning, language attitudes and ideologies, and motivation in second language acquisition.

Martin Howard is Head of the School of Languages, Literatures and Cultures at University College Cork, Ireland. He is Editor of the journal Study Abroad Research in Second Language Acquisition and International Education, and Chair of the European COST Action, Study Abroad Research in European Research.

\section{References}

Al-Hoorie, A. H. (2017). Sixty years of language motivation research: looking back and looking forward. SAGE Open 7(1): 1-11.

Al-Hoorie, A. H. (2018). The L2 motivational self system: a meta-analysis. Studies in Second Language Learning and Teaching 8(4): 721-754.

Boo, Z., Dörnyei, Z. and Ryan, S. (2015). L2 motivation research 2005-2014: understanding a publication surge and a changing landscape. System 55: 145-157.

Busse, V. and Williams, M. (2010). Why German? Motivation of students studying German at English universities. The Language Learning Journal 38: 67-85.

Coetzee-Van Rooy, S. (2006) Integrativeness: untenable for world Englishes learners? World Englishes 25: 437-450.

Crookes, G. and Schmidt, R. (1991). Motivation: reopening the research agenda. Language Learning 41: 469-512.

Deci, E. L. and Ryan, R. M. (1985). Intrinsic Motivation and Self-determination in Human Behavior. New York: Plenum.

Dörnyei, Z. (1994). Understanding L2 motivation: on with the challenge! The Modern Language Journal 78: 515-523. 
Dörnyei, Z. (2005). The Psychology of the Language Learner: Individual Differences in Second Language Acquisition. Mahwah: Lawrence Erlbaum.

Dörnyei, Z. (2009). The L2 motivational self. In Z. Dörnyei and E. Ushioda (eds.) Motivation, Language Identity and the L2 Self. Bristol: Multilingual Matters, 9-42.

Dörnyei, Z. (2010). Researching motivation: from integrativeness to the ideal L2 self. In S. Hunston and D. Oakey (eds.) Introducing Applied Linguistics: Concepts and Skills. New York: Routledge, 74-83.

Dörnyei, Z. and Chan, L. (2013). Motivation and vision: an analysis of future L2 self images, sensory styles, and imagery capacity across two target languages. Language Learning 63: 437-462.

Dörnyei, Z. and Clément, R. (2001). Motivational characteristics of learning different target languages: Results of a nationwide survey. In Z. Dörnyei and R. Schmidt (eds.) Motivation and Second Language Acquisition. Honolulu: University of Hawai'i Press, 399-432.

Dörnyei, Z. and Csizér, K. (2002) Some dynamics of language attitudes and motivation: Results of a longitudinal nationwide survey. Applied Linguistics 23: 421-62.

Dörnyei, Z. and Ryan, S. (2015). The Psychology of the Language Learner Revisited. New York: Routledge.

Dörnyei, Z. and Ushioda, E. (2011). Teaching and Researching Motivation. 2nd edition. New York: Longman.

Dörnyei, Z., Csizér, K. and Németh, N. (2006). Motivation, Language Attitudes and Globalisation: A Hungarian Perspective. Clevedon: Multilingual Matters.

Dörnyei, Z., MacIntyre, P. D. and Henry, A. (eds.) (2015). Motivational Dynamics in Language Learning. Bristol: Multilingual Matters.

Gardner, R. C. (1985). Social Psychology and Second Language Learning: The Role of Attitudes and Motivation. London: Edward Arnold.

Gardner, R. C. (2001). Integrative motivation and second language acquisition. In Z. Dörnyei and R. Schmidt (eds.) Motivation and Second Language Acquisition. Honolulu: University of Hawai'i Press, 1-19.

Gardner, R. C. (2005). Integrative motivation and second language acquisition. Canadian Association of Applied Linguistics/Canadian Linguistics Association, Joint Plenary Talk, London, Ontario, May 30, 2005. Accessed 11 July 2018 at http://publish.uwo.ca/ gardner/docs/caaltalk5final.pdf

Gardner, R. C. (2010). Motivation and Second Language Acquisition: The Socio-educational Model. New York: Peter Lang.

Gardner, R. C., Tremblay, P. F. and Masgoret, A.-M. (1997). Towards a full model of second language learning: an empirical investigation. The Modern Language Journal 81: $344-362$.

Henry, A. (2015). The dynamics of possible selves. In Z. Dörnyei, P. D. MacIntyre and A. Henry (eds.) Motivational Dynamics in Language Learning. Bristol: Multilingual Matters, 83-94.

Hernández, T. A. (2010). The relationship among motivation, interaction and the development of second language oral proficiency in a study-abroad context. The Modern Language Journal 94: 600-617.

Higgins, E. T. (1987). Self-discrepancy: A theory relating self and affect. Psychological Review 94: 319-340.

Higgins, E. T. (1998). Promotion and prevention: Regulatory focus as a motivational principle. Advances in Experimental Social Psychology 30: 1-46.

Howard, M. and Oakes, L. (forthcoming). Second language motivation among university learners of French: a cross-country comparison on the effect of English. 
Isabelli-García, C. (2006). Study abroad social networks, motivation and attitudes: implications for second language acquisition. In M. A DuFon and E. Churchill (eds.) Language Learners in Study Abroad Contexts. Clevedon: Multilingual Matters, 231-258.

Juan-Garau, M., Salazar-Noguerra, J. and Prieto-Arranz, J. I. (2014). English L2 learners' lexico-grammatical and motivational development at home and abroad. In C. Pérez-Vidal (ed.) Language Acquisition in Study Abroad and Formal Instruction Contexts. Amsterdam/Philadelphia: John Benjamins, 235-258.

Kormos, J. and Csizér, K. (2008). Age-related differences in the motivation of learning English as a foreign language: Attitudes, selves, and motivated learning behavior. Language Learning 58(2): 327-355.

Lamb, M. (2004). Integrative motivation in a globalizing world. System 32: 3-19.

Lance, C. E., Butts, M. M. and Michels, L. C. (2006). The sources of four commonly reported cutoff criteria: what did they really say? Organizational Research Methods 9: 202-220.

Lockwood, P. and Kunda, Z. (1997). Superstars and me: predicting the impact of role models on the self. Journal of Personality and Social Psychology 73: 91-103.

MacIntyre, P. D. and Serroul, A. (2015). Motivation on a per-second timescale: examining approach-avoidance motivation during L2 task performance. In Z. Dörnyei, P. D. MacIntyre and A. Henry (eds.) Motivational Dynamics in Language Learning. Bristol: Multilingual Matters, 109-138.

MacIntyre, P. D., MacKinnon, S. P. and Clément, R. (2009). The baby, the bathwater, and the future of language learning motivation research. In Z. Dörnyei and E. Ushioda (eds.) Motivation, Language Identity and the L2 Self. Bristol: Multilingual Matters, 43-65.

Markus, H. R. and Nurius, P. (1986). Possible selves. American Psychologist 41: 954-969.

McClelland, N. (2000). Goal orientations in Japanese college students learning EFL. In S. D. Cornwell and P. Robinson (eds.) Individual Differences in Foreign Language Learning: Effects of Aptitude, Intelligence, and Motivation. Tokyo: Japanese Association for Language Teaching, 99-115.

McDonough, S. (1986). Psychology in Foreign Language Teaching. 2nd edition. London: Unwin Hyman.

Noels, K. A. (2001). New orientations in language learning motivation: towards a model of intrinsic, extrinsic and integrative orientations and motivation. In Z. Dörnyei and R. Schmidt (eds.) Motivation and Second Language Acquisition. Honolulu: University of Hawai'i, 43-68.

Noels, K. A. (2009). The internalisation of language learning into the self and social identity. In Z. Dörnyei and E. Ushioda (eds.) Motivation, Language Identity and the L2 Self. Bristol: Multilingual Matters, 295-313.

Noels, K. A., Pelletier, L. G., Clément, R. and Vallerand, R. J. (2000). Why are you learning a second language? Motivational orientations and self-determination theory. Language Learning 50: 57-85.

Norton, B. (2001). Non-participation, imagined communities and the language classroom. In M. P. Breen (Ed.), Learner contributions to language learning. Harlow: Longman, 159171.

Oakes, L. (2013). Foreign language learning in a 'monoglot culture': motivational variables amongst students of French and Spanish at an English university. System 41: 178-191.

Ryan, R. M. and Deci, E. L. (2000). Self-determination theory and the facilitation of intrinsic motivation, social development, and well-being. American Psychologist 55: 68-78.

Ryan, S. (2008). The Ideal L2 Selves of Japanese Learners of English. Unpublished doctoral dissertation, University of Nottingham. 
Shaw, W. D. (1983). Asian student attitudes towards English. In L. E. Smith (ed.) Readings in English as an International Language. Oxford: Pergamon Institute of English, 21-33.

Sridhar, K. K. and Sridhar, S. N. (1992). Bridging the paradigm gap: second-language acquisition theory and indigenized varieties of English. In B. B. Kachru (ed.) The Other Tongue: English across Cultures. Urbana: University of Illinois Press, 91-107.

St-Laurent, N., with the collaboration of Maraillet, E., Chastenay, M.-H. and Tessier, C. (2008). Le français et les jeunes. Québec, Canada: Conseil supérieur de la langue française.

Taguchi, T., Magid, M. and Papi, M. (2009). The L2 motivational self system among Chinese, Japanese and Iranian learners of English: a comparative study. In Z. Dörnyei and E. Ushioda (eds.) Motivation, Language Identity and the L2 Self. Bristol, UK: Multilingual Matters, 66-97.

Ushioda, E. (2017). The impact of global English on motivation to learn other languages: Toward an ideal multilingual self. The Modern Language Journal 101: 469-482.

Ushioda, E. and Dörnyei, Z. (2009). Motivation, language identity and the L2 self: a theoretical overview. In Z. Dörnyei and E. Ushioda (eds.) Motivation, Language Identity and the L2 Self. Bristol: Multilingual Matters, 1-8.

Ushioda, E. and Dörnyei, Z. (2017). Beyond global English: motivation to learn languages in a multicultural world: introduction to the special issue. The Modern Language Journal 101: 451-454.

Velicer, W. F., Eaton, C. A. and Fava, J. L. (2000). Construct explication through factor analysis: a review and evaluation of alternative procedures for determining the number of factors or components. In R. D. Goffin and E. Helmes (eds.) Problems and Solutions in Human Assessment: Honoring Douglas N. Jackson at Seventy. Norwell: Kluwer Academic, 41-72.

Yashima, T. (2002). Willingness to communicate in a second language: the Japanese EFL context. The Modern Language Journal 86: 54-66.

\section{Appendix: questionnaire items}

Ideal L2 self $(\alpha=$.79)

6 Being able to converse in French/English is an important part of the person I want to become

9 If my dreams come true, I will use French/English effectively in the future

18 I can imagine myself as someone who is able to use French/English well

31 Whenever I think of my future, I imagine myself being able to use French/English

\section{Ought-to L2 self $(\alpha=$.78)}

7 I consider learning French/English important because the people I respect think that I should do so

15 People around me (e.g. parents, partner) believe that I ought to study French/English

19 I study French/English because people around me expect me to do so

26 If I fail to learn French/English, I will be letting other people down

\section{Strong integrative $(\alpha=.72)$}

11 I am studying French/English because I would like to live in a French/English-speaking country 
20 Knowing French/English will allow me to become more like people from French/Englishspeaking countries

24* I am learning French/English because I would like to feel at ease in French/Englishspeaking countries

29 I like learning French/English because I feel an affinity with people in French/Englishspeaking countries

\section{Weak integrative $(\alpha=.74)$}

10 Learning French/English provides an opportunity to appreciate a francophone way of life

14 Learning French/English will help me to better understand the cultures and societies of the French/English-speaking world

$27^{*}$ Knowing French/English allows me to enjoy interesting cultural activities in French/English (e.g. reading, watching movies, listening to music)

32 Studying French/English allows me to enjoy rich and diverse cultures

Instrumental $(\alpha=.85)$

4 Knowing French/English will help me to obtain a better job

17* I think knowing French/English will help me to become a more knowledgeable person

25 I think French/English will help in my future career

33 Studying French/English will enhance my professional profile and CV

\section{Intrinsic}

3* I really enjoy learning French/English

$13 *$ Learning French/English is one of the most important aspects of my life

$22 *$ It is personally satisfying to be able to communicate in French/English

$28 *$ I like the challenge of learning French/English

\section{Desire for proficiency $(\alpha=.92)$}

1 I am studying French/English because I want to improve my French/English

2 By studying French/English I hope to improve my speaking skills in French/English

5 By studying French/English I hope to improve my reading skills in French/English

12 By studying French/English I hope to improve my written French/English

21 By studying French/English I hope to improve my listening comprehension in French/English

\section{Self-reported proficiency $(\alpha=.92)$}

- How would you rate your speaking skills in French/English?

- How would you rate your listening skills in French/English?

- How would you rate your writing skills in French/English?

- How would you rate your reading skills in French/English?

* denotes deleted item 
Table 1. Distribution of respondents according to country and target language

\begin{tabular}{lccc} 
& French & English & Total \\
\hline Sweden & 101 & 103 & 204 \\
Poland & 125 & 193 & 318 \\
Total & 226 & 296 & 522 \\
\hline
\end{tabular}


Table 2. Length of study according to target language

$$
\text { French English }
$$

\begin{tabular}{lrrrr} 
& $n$ & $\%$ & $n$ & $\%$ \\
\hline$<1$ year & 66 & 30.0 & 23 & 7.8 \\
1-5 years & 98 & 44.5 & 19 & 6.5 \\
$>$ 5 years & 56 & 25.5 & 252 & 85.7 \\
\hline
\end{tabular}


Table 3. Factor analysis results

\begin{tabular}{|c|c|c|c|c|c|c|}
\hline $\begin{array}{c}\text { Item } \\
\text { number }\end{array}$ & $\begin{array}{l}\text { Desire for } \\
\text { proficiency }\end{array}$ & $\begin{array}{l}\text { Ought-to } \\
\text { L2 self }\end{array}$ & $\begin{array}{l}\text { Ideal L2 } \\
\text { self }\end{array}$ & Instrumental & $\begin{array}{c}\text { Weak } \\
\text { integrative }\end{array}$ & $\begin{array}{c}\text { Strong } \\
\text { integrative }\end{array}$ \\
\hline 2 & 0.95 & 0.00 & 0.09 & -0.07 & -0.13 & 0.03 \\
\hline 1 & 0.89 & -0.04 & 0.04 & -0.08 & -0.10 & 0.04 \\
\hline 12 & 0.84 & -0.01 & -0.10 & 0.11 & 0.01 & 0.05 \\
\hline 5 & 0.82 & -0.03 & -0.08 & -0.01 & 0.14 & -0.01 \\
\hline 21 & 0.73 & -0.01 & -0.02 & 0.07 & 0.11 & -0.05 \\
\hline 19 & -0.03 & 0.82 & -0.17 & -0.02 & -0.05 & -0.01 \\
\hline 7 & 0.08 & 0.72 & 0.04 & -0.01 & -0.01 & -0.05 \\
\hline 15 & -0.01 & 0.71 & 0.14 & 0.01 & -0.04 & -0.09 \\
\hline 26 & -0.10 & 0.57 & -0.09 & 0.01 & -0.01 & 0.12 \\
\hline 31 & -0.05 & -0.09 & 0.78 & 0.12 & -0.07 & 0.01 \\
\hline 18 & -0.03 & -0.07 & 0.75 & 0.02 & -0.04 & 0.05 \\
\hline 9 & 0.23 & 0.14 & 0.47 & 0.04 & 0.07 & -0.06 \\
\hline 6 & 0.18 & 0.11 & 0.46 & 0.02 & 0.01 & 0.05 \\
\hline 25 & -0.10 & -0.04 & 0.11 & 0.85 & 0.01 & 0.05 \\
\hline 4 & -0.01 & 0.02 & 0.09 & 0.79 & -0.07 & 0.01 \\
\hline 33 & 0.15 & 0.02 & -0.03 & 0.68 & 0.02 & -0.09 \\
\hline 14 & 0.02 & -0.16 & -0.14 & 0.04 & 0.86 & 0.02 \\
\hline 10 & 0.02 & 0.11 & 0.08 & -0.10 & 0.68 & 0.00 \\
\hline 32 & -0.06 & -0.03 & 0.37 & 0.02 & 0.43 & 0.02 \\
\hline 29 & -0.06 & -0.02 & 0.10 & -0.04 & -0.01 & 0.74 \\
\hline 11 & 0.10 & -0.10 & 0.05 & -0.02 & -0.07 & 0.71 \\
\hline 20 & 0.00 & 0.19 & -0.14 & 0.09 & 0.16 & 0.55 \\
\hline
\end{tabular}

Note. Since factor rotation was used, the order of the factors does not necessarily represent their degree of importance. As is the case with oblique rotation, it was not possible to determine how much variance was accounted for by each individual factor. 
Table 4. Ratings for motivational constructs according to target language

\begin{tabular}{llccccccc} 
& Language & $n$ & $M$ & $S D$ & $t$ & $d f$ & $p$ & $d$ \\
\hline Desire for & French & 226 & 4.66 & 0.71 & 3.76 & 505.76 & .000 & 0.33 \\
proficiency & English & 296 & 4.41 & 0.79 & & & & \\
\hline Instrumental & French & 223 & 4.14 & 0.86 & -3.11 & 449.95 & .002 & -0.28 \\
& English & 290 & 4.37 & 0.77 & & & & \\
\hline Ideal L2 self & French & 226 & 4.19 & 0.82 & -1.60 & 520 & .110 & -0.14 \\
& English & 296 & 4.30 & 0.77 & & & & \\
\hline Weak & French & 226 & 3.97 & 0.89 & 2.87 & 520 & .004 & 0.25 \\
integrative & English & 296 & 3.75 & 0.82 & & & & \\
\hline Strong & French & 225 & 2.72 & 1.00 & 1.49 & 517 & .136 & 0.13 \\
integrative & English & 294 & 2.59 & 1.03 & & & & \\
\hline Ought-to L2 & French & 226 & 2.16 & 1.04 & -5.65 & 520 & .000 & -0.50 \\
self & English & 296 & 2.65 & 0.95 & & & & \\
\hline
\end{tabular}


Table 5. Correlations (Pearson's $r$ ) between motivational constructs

\begin{tabular}{lccccc}
\hline & $\begin{array}{c}\text { Desire for } \\
\text { proficiency }\end{array}$ & Instrumental & $\begin{array}{c}\text { Ideal } \\
\text { L2 self }\end{array}$ & $\begin{array}{c}\text { Weak } \\
\text { integrative }\end{array}$ & $\begin{array}{c}\text { Strong } \\
\text { integrative }\end{array}$ \\
\hline Instrumental & $.49^{* *}$ & & & & \\
Ideal L2 self & $.61^{* *}$ & $.64^{* *}$ & & & \\
Weak integrative & $.44^{* *}$ & $.43^{* *}$ & $.51^{* *}$ & & \\
Strong integrative & .07 & $.09^{*}$ & $.16^{* *}$ & $.41^{* *}$ & \\
Ought-to L2 self & $-.12^{*}$ & $.15^{* *}$ & .08 & .08 & $.22^{* *}$ \\
\hline$* p<0.05, * * p<.001$ & & & &
\end{tabular}


Table 6. ANOVA comparisons of ratings for strong integrative orientation according to length of study by target language

\begin{tabular}{lccccccccc}
\hline & & & & & & & & \multicolumn{2}{c}{$\begin{array}{c}\text { Bonferroni } \\
\text { comparisons }\end{array}$} \\
\cline { 8 - 10 } Language & $\begin{array}{c}\text { cength of } \\
\text { study }\end{array}$ & $n$ & $M$ & $S D$ & $F$ & $d f$ & $p$ & $<1$ year & $1-5$ years \\
\hline French & $<1$ year & 65 & 2.47 & 1.06 & 3.26 & 2,216 & .040 & & \\
& $1-5$ years & 98 & 2.77 & 0.99 & & & & .203 & \\
& $>5$ years & 56 & 2.92 & 0.94 & & & & .042 & 1.000 \\
\hline English & $<1$ year & 23 & 3.07 & 0.90 & 3.19 & 2,289 & .043 & & \\
& $1-5$ years & 19 & 2.75 & 0.99 & & & & .941 & \\
& $>5$ years & 250 & 2.54 & 1.03 & & & & .048 & 1.000 \\
\hline
\end{tabular}


Table 7. ANOVA comparisons of ratings for ought-to L2 self according to length of study by target language

\begin{tabular}{lccccccccc}
\hline & & & & & & & & \multicolumn{2}{c}{$\begin{array}{c}\text { Bonferroni } \\
\text { comparisons }\end{array}$} \\
\cline { 7 - 10 } Language & study & $n$ & $M$ & $S D$ & $F$ & $d f$ & $p$ & $<1$ year & $1-5$ years \\
\hline French & $<1$ year & 66 & 1.98 & 1.03 & 2.90 & 2,218 & .057 & & \\
& $1-5$ years & 98 & 2.14 & 1.05 & & & & & \\
& $>5$ years & 56 & 2.43 & 1.04 & & & & & \\
\hline English & $<1$ year & 23 & 1.94 & 0.83 & 7.39 & 2,291 & .001 & & \\
& $1-5$ years & 19 & 2.68 & 0.99 & & & & .029 & \\
& $>5$ years & 252 & 2.71 & 0.93 & & & & .000 & 1.000 \\
\hline
\end{tabular}




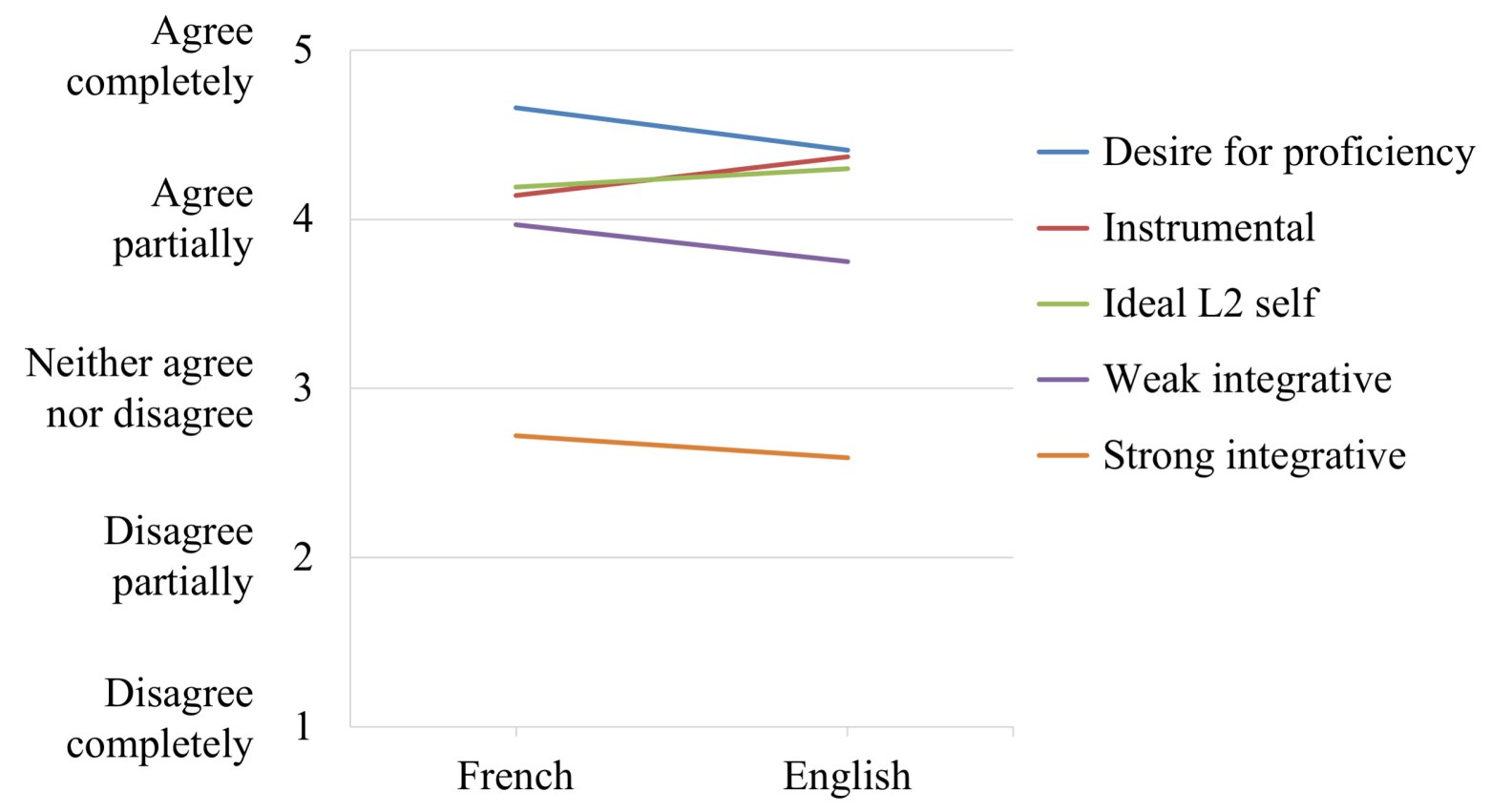

Figure 1. Patterns of motivational constructs across French and English learners 